\title{
Systematic and Liquidity Risk in Subprime-Mortgage Backed Securities
}

\author{
Mardi Dungey • Gerald P. Dwyer • Thomas Flavin
}

Published online: 9 October 2012

(C) Springer Science+Business Media New York 2012

\begin{abstract}
The misevaluation of risk in securitized financial products is central to understanding the Financial Crisis of 2007-2008. This paper characterizes the evolution of factors affecting collateralized debt obligations (CDOs) based on subprime mortgages. A key feature of subprime-mortgage backed indices is that they are distinct in their vintage of issuance. Using a latent factor framework that incorporates this vintage effect, we show the increasing importance of a common factor on more senior tranches during the crisis. We examine this common factor and its relationship with spreads. We estimate the effects of the financial crisis on the common factor.
\end{abstract}

Keywords Asset backed securities $\cdot$ Subprime mortgages $\cdot$ Financial crisis $\cdot$ Factor models $\cdot$ Kalman filter

JEL Classification $\mathrm{G} 12 \cdot \mathrm{G} 01 \cdot \mathrm{C} 32$

\author{
M. Dungey \\ University of Tasmania, Private Bag 85, Hobart, Tasmania 7001, Australia
}

M. Dungey

CFAP, University of Cambridge, Cambridge, UK

M. Dungey $\cdot$ G. P. Dwyer

CAMA, Australian National University, Canberra, Australia

G. P. Dwyer $(\square)$

Departmento de la Economía de la Empresa, Universidad Carlos III de Madrid, Calle Madrid 126, 28903 Getafe, Madrid, Spain

e-mail: gpdwyer@gmail.com

T. Flavin

National University of Ireland, Maynooth, Room 56, Rhetoric House, NUI Maynooth, Co., Kildare, Ireland 


\section{Introduction}

Securities based on subprime mortgages played a central role in the Financial Crisis of 2007-2008. The shortcomings of models for pricing these securities became apparent when real estate prices started to fall and mortgages became delinquent. Difficulties valuing these securities led to widespread problems trading them, (Dwyer and Tkac 2011).

The period leading up to the crisis was one of dramatic growth in asset backed securities and structured financial products. These products were tranched and rated and acquired by investors across the world. Chiesa (2008) shows that pooled and tranched securities can generate optimal risk transfer, although one rationale for the issuance of pooled and tranched securities is an informational advantage about underlying asset quality enjoyed by informed sellers (DeMarzo 2005). Increased demand for structured securities led to an expansion in the range of underlying assets (Benmelech and Dlugosz 2009) and the creation of structured securities based on subprime mortgages increased dramatically. Mian and Sufi (2009) provide evidence that an increased demand for these products affected the market for subprime mortgages by resulting in less stringent lending criteria and contributing to their subsequent growth.

The spread of this crisis from a relatively small sector of the financial system across markets and international borders resulted in widespread financial distress. ${ }^{1}$ Among other effects, banks in much of the world suffered substantial losses followed by serious retrenchment and restructuring. The turbulence and ensuing lack of confidence spread to other asset markets and the real economy. Brunnermeier (2009), Dwyer and Tkac (2009) and others document the evolution and spread of the crisis and the role of subprime-mortgage backed securities in it.

The misperception and misevaluation of risk in structured financial products is central to many explanations of the financial crisis. This may have arisen partly due to the failure of some market participants to differentiate between the risk of AAA-rated tranches of Collateralized Debt Obligations (CDOs) and AAA-rated corporate bonds (Brennan et al. 2009). In addition to possible mispricing, the valuation of CDO tranches is particularly problematic in the event of widespread defaults (Smithson 2009), a feature not apparent before defaults increased in 2007. Valuation models have four key inputs: default rates, prepayment risk, recovery rates and default correlations. Problems estimating the last two were important during the financial crisis. Default correlations inevitably are based on historical data and were underestimated based on a period of increasing house prices and economic expansion. As default correlations increase, the probability of observing large-scale defaults also increases, causing the prices of senior CDO tranches to fall. Estimates of recovery rates were also affected. Consequently, the risk priced in the different CDO tranches was underestimated. Coval et al. (2009) analyze the risk inherent in the securitization process and in particular how risk migrates to higher-rated tranches in the event of increasing importance of a large common shock such as falling house prices.

\footnotetext{
${ }^{1}$ Dwyer and Tkac (2009) estimate that subprime mortgages are no more than one percent of global bond values, stock values and bank deposits
} 
A better understanding of the factors underlying price changes in these subprimemortgage backed assets is important for understanding their role in the crisis. We characterize the driving forces behind the decreases in these securities' prices. In earlier work, Longstaff and Rajan (2008) show that a theoretical pricing model for CDOs can be represented as a three factor model, with common, credit rating and idiosyncratic shocks. An empirical application using tranches of corporate credit default swap indices (CDX) from 2003 to 2005 suggests that idiosyncratic default risk accounts for around $65 \%$ of the risk premium, while common risk accounts for only $8 \%$ of that premium. Extending the time period, Bhansali et al. (2008) show a substantial increase in common-event risk in 2007 and 2008.

An additional but potentially key feature of subprime-mortgage backed indices is variation in the quality of the underlying loans and collateral over time. Demyanyk and Van Hemert's (2011) analysis of subprime loans indicates a gradual and persistent deterioration of loan quality from 2001 to 2007. To reflect this deterioration, we extend Longstaff and Rajan's (2008) empirical model to include a fourth factor, a vintage factor. This vintage factor reflects risks associated with the dates the securities were created. The model is applied to asset tranches of mortgage backed securities using the Markit ABX.HE indices for three vintages over the period January 2006 to December 2009. An innovation of this paper is the exploitation of the unbalanced panel structure of the data to identify the vintage, credit, common and idiosyncratic effects. This allows us to assess the contribution of all factors to the asset prices and returns. We specify the model in state-space form and estimate it with a Kalman filter.

The ABX.HE data have been examined in several studies of the financial crisis. Fender and Scheicher (2009) use two vintages to track the crisis and find that increased liquidity risk and decreasing risk appetite were important factors in the price decreases of the higher-rated tranches. Our paper differs in many respects; we extract risk factors differently and focus on the level rather than the change of the common factor. Longstaff (2010) uses the ABX indices to test for contagion from the subprime-asset backed market to other parts of the financial system. He finds strong evidence of contagion and liquidity risk with revisions to risk premia identified as the most likely transmission channel. Longstaff also finds that ABX returns lead stock market returns and bond yield changes by up to 3 weeks, suggesting that significant information was uncovered in this market that led to subsequent price changes in other markets. Gorton (2009) finds that declines in the ABX indices and the repo market were highly correlated due to some combination of counterparty risk and lack of liquidity.

Our results summarize the behaviour of subprime-mortgage backed securities in terms of four factors. In 2006, all factors have a discernible role in asset returns. The common factor becomes more important when the financial turmoil begins and has a larger effect on AAA tranches than in the pre-crisis period. We examine the common factor's relationship with observable factors including real estate prices, the VIX index and interest rate spreads which reflect the financial crisis. We find that liquidity and counterparty risk, as represented by the spread between the London Interbank Borrowing Rate (LIBOR) and the Overnight Index Swap (OIS) rate, is sufficient to characterize the relationship between the common factor and the financial crisis as reflected in interest rate spreads. We undertake a counterfactual analysis of the evolution of the common factor if the LIBOR-OIS spread had remained at pre- 


\section{ABX Indices by Vintage}

06-1 vintage

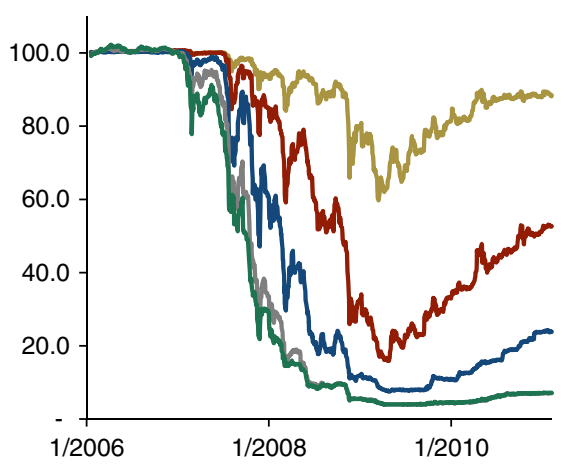

AAA

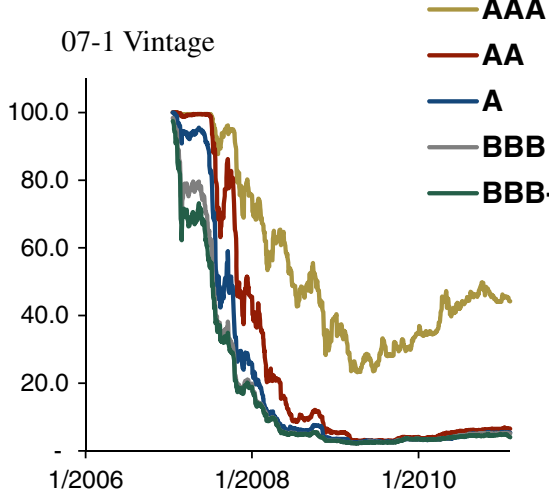

06-2 Vintage

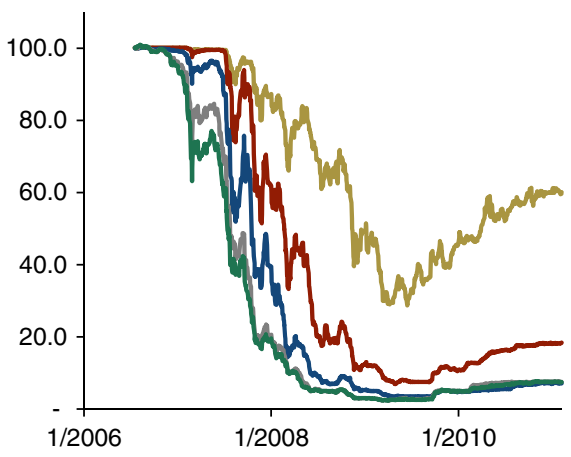

07-2 Vintage

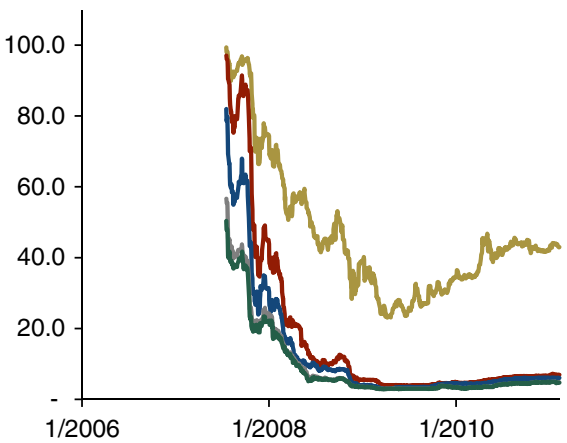

Fig. $1 \mathrm{ABX}$ indices by vintage. This figure shows the levels of the Markit ABX indices of Collateralized Debt Obligations based on subprime mortgages. The data are from Haver Analytics. The vintages are January 2006 (06-1), July 2006 (06-2), January 2007 (07-1) and July 2007 (07-2). No indices have been created subsequently. The premium is set on the indices to have an initial value of 100 based on a survey of market participants, unless that premium is over 500 basis points in which case the premium is 500 basis points. The initial trading values were less than 100 for lower rated tranches in the January 2007 vintage and for the July 2007 vintages

crisis levels throughout. We estimate that the common factor is $20 \%$ lower at the end of 2009 than it would have been if LIBOR-OIS had not been elevated during the financial crisis. Likewise we estimate that the actual value of the REIT index is about $40 \%$ lower and VIX some $50 \%$ higher than in the simulated model with a stable interest rate spread. The decreases in the common factor, decreases in the REIT index and increases of VIX are the estimated effects of the elevated values of LIBOR-OIS during the crisis, not effects of lower housing prices. ${ }^{2}$

The paper is structured as follows. Section 2 describes the ABX data and highlights its unique features which are reflected in the econometric model presented in

\footnotetext{
${ }^{2}$ A REIT index is included with the common factor in a cointegrating vector in order to reflect the stochastic trend in housing prices.
} 
Section 3. The estimates of the factors are discussed in Section 4. Section 5 relates the common factor to observable short-term fixed-income spreads. Section 6 concludes.

\section{Tracking the Market for Subprime Mortgages}

The price decreases in asset backed securities during the financial difficulties of 2007 to 2009 were dramatic. They represent declines in the values of the underlying assets but probably also reassessments of the risks and liquidity of such assets. We analyze the risk factors inherent in these tranched pools by examining the relatively new indices of CDOs used as the basis for credit default swaps related to subprimemortgage backed securities. These indices, entitled ABX.HE, were introduced in January 2006 by Markit and are widely used by market participants to track the market for subprime mortgages and to bet on it.

Figure 1 shows the evolution of the indices from January 2006 to December 31, 2009. Each issue is subdivided into five tranches, varying from AAA to BBB-, where the ratings are the lower of those issued by Moody's and S\&P. The index values are derived from underlying credit default swaps with the insurance coupon fixed for the life of trading. The coupon is set so the index trades at par - 100 - at inception unless such a coupon exceeds 500 basis points, in which case the coupon is set at 500 basis points.

Each vintage of the index is based on twenty mortgage backed CDO deals created within the previous 6 months. For example, the ABX.HE 06-1 index is constructed from deals created in the second half of 2005 . The issuers are the largest originators. ${ }^{3}$ Strict requirements must be met to qualify for inclusion in the index. For example, the value of each deal must be at least $\$ 500$ million and each tranche must have an average life between 4 and 6 years, and the AAA tranche must have a weighted average life of more than 5 years. Furthermore, no security originator can have more than four deals included.

New indices were created every 6 months from January 2006 to July 2007. No indices have been created since then because there are too few new CDOs meeting the eligibility requirements. ${ }^{4}$ New indices every 6 months with similar underlying securities might have created an index that could be spliced together as is done sometimes with onthe-run bonds and futures prices. Each vintage represents quite different risks though. At least part of the explanation for these vintage effects is an increase in the riskiness of the underlying mortgages (Demyanyk and Van Hemert 2011). This increase in risk is reflected in increased coupon rates for insurance on the ABX indices from 2006 to 2007. Figure 1 shows substantial heterogeneity in the index values across vintages from 2006 to the end of 2009 with later values declining more, which is consistent with the mortgages being riskier. These considerations suggest that successive rolls of the ABX are not suitable for splicing to create a continuous series, as Longstaff and Rajan (2008) do for CDX data. Instead, each new index is best viewed as a unique vintage with the risk of the underlying pool of assets different between vintages.

\footnotetext{
${ }^{3}$ Licensed dealers in the ABX.HE indices included ABN AMRO, Bank of America, Barclays Capital, Bear Stearns, BNP Paribas, Calyon, Citigroup, Credit Suisse, Deutsche Bank, Goldman Sachs, JPMorgan, Lehman Brothers, Merrill Lynch, Morgan Stanley, RBS Greenwich, UBS and Wachovia.

${ }^{4}$ As of this writing in 2012, there has been very little securitization since 2008.
} 
Our initial analysis extracts a common factor from the behaviour of daily $\mathrm{ABX}$ returns. These "returns" on the ABX are the differences in the logarithms of the indices. Descriptive statistics for each tranche of each vintage are given in Table 1. The data set is unbalanced; all vintages exist at the end of the period but the vintages are created over time. Within each vintage, the standard deviation of returns is lowest for the AAA security. The first vintage has returns with the lowest volatility and there is some evidence of higher standard deviations of returns for later vintages. The distributions are negatively skewed with the exception of the AAA tranche of the final vintage. All assets display excess kurtosis. This is greatest for the first vintage, possibly reflecting the sustained low-variance period at the start of the period.

Tables 2 and 3 present correlations of the returns across credit ratings for given vintages and across vintages for given credit ratings. The correlations of the AAA tranches with other tranches decrease monotonically as ratings decline. The

Table 1 Summary statistics for asset returns by vintage

\begin{tabular}{|c|c|c|c|c|c|c|c|}
\hline Rating & Mean & $\begin{array}{l}\text { Standard } \\
\text { deviation }\end{array}$ & Minimum & Maximum & Skewness & $\begin{array}{l}\text { Excess } \\
\text { kurtosis }\end{array}$ & $\begin{array}{l}\text { Number of } \\
\text { observations }\end{array}$ \\
\hline \multicolumn{8}{|c|}{ Vintage $06-1$} \\
\hline AAA & -0.0002 & 0.0091 & -0.082 & 0.076 & -0.842 & 18.900 & 990 \\
\hline AA & -0.0011 & 0.0191 & -0.140 & 0.143 & -0.180 & 13.518 & 990 \\
\hline A & -0.0022 & 0.0213 & -0.132 & 0.105 & -0.421 & 7.575 & 990 \\
\hline $\mathrm{BBB}$ & -0.0031 & 0.0218 & -0.206 & 0.107 & -2.905 & 22.872 & 990 \\
\hline BBB- & -0.0031 & 0.0201 & -0.187 & 0.112 & -1.822 & 14.126 & 990 \\
\hline \multicolumn{8}{|c|}{ Vintage $06-2$} \\
\hline AAA & -0.0009 & 0.0168 & -0.082 & 0.114 & -0.397 & 6.924 & 865 \\
\hline $\mathrm{AA}$ & -0.0026 & 0.0222 & -0.110 & 0.134 & -0.324 & 6.256 & 865 \\
\hline $\mathrm{A}$ & -0.0035 & 0.0246 & -0.172 & 0.105 & -1.043 & 7.085 & 865 \\
\hline $\mathrm{BBB}$ & -0.0035 & 0.0241 & -0.134 & 0.177 & -0.261 & 7.573 & 865 \\
\hline BBB- & -0.0035 & 0.0237 & -0.112 & 0.116 & -0.059 & 4.074 & 865 \\
\hline \multicolumn{8}{|c|}{ Vintage $07-1$} \\
\hline AAA & -0.0014 & 0.0211 & -0.114 & 0.139 & -0.061 & 6.710 & 739 \\
\hline $\mathrm{AA}$ & -0.0043 & 0.0261 & -0.156 & 0.101 & -0.868 & 5.265 & 739 \\
\hline A & -0.0046 & 0.0282 & -0.189 & 0.093 & -0.893 & 5.269 & 739 \\
\hline $\mathrm{BBB}$ & -0.0045 & 0.0261 & -0.185 & 0.105 & -0.858 & 5.686 & 739 \\
\hline BBB- & -0.0045 & 0.0249 & -0.181 & 0.092 & -0.875 & 5.201 & 739 \\
\hline \multicolumn{8}{|c|}{ Vintage $07-2$} \\
\hline AAA & -0.0017 & 0.0227 & -0.104 & 0.139 & 0.057 & 6.093 & 613 \\
\hline $\mathrm{AA}$ & -0.0049 & 0.0278 & -0.140 & 0.148 & -0.888 & 5.843 & 613 \\
\hline A & -0.0047 & 0.0260 & -0.142 & 0.091 & -0.623 & 3.517 & 613 \\
\hline $\mathrm{BBB}$ & -0.0046 & 0.0247 & -0.199 & 0.086 & -1.217 & 8.121 & 613 \\
\hline BBB- & -0.0044 & 0.0248 & -0.156 & 0.090 & -0.871 & 4.906 & 613 \\
\hline
\end{tabular}

This table presents summary statistics for all vintages and all ratings of the ABX index for all dates from inception to December 31, 1999. The left-skewness and excess kurtosis of the returns for all vintages and ratings is evident 
Table 2 Correlations of returns across credit ratings with vintages

\begin{tabular}{|c|c|c|c|c|c|c|c|c|c|c|}
\hline Rating & $\mathrm{AAA}$ & $\mathrm{AA}$ & A & BBB & BBB- & AAA & $\mathrm{AA}$ & A & BBB & BBB- \\
\hline & \multicolumn{5}{|c|}{ Vintage 06-1 } & \multicolumn{5}{|c|}{ Vintage $06-2$} \\
\hline AAA & 1 & & & & & 1 & & & & \\
\hline $\mathrm{AA}$ & .833 & 1 & & & & .599 & 1 & & & \\
\hline A & .492 & .594 & 1 & & & .396 & .638 & 1 & & \\
\hline BBB & .381 & .415 & .649 & 1 & & .220 & .435 & .581 & 1 & \\
\hline \multirow[t]{2}{*}{ BBB- } & .395 & .428 & .595 & .837 & 1 & .190 & .402 & .509 & .740 & 1 \\
\hline & \multicolumn{5}{|c|}{ Vintage $07-1$} & \multicolumn{5}{|c|}{ Vintage $07-2$} \\
\hline AAA & 1 & & & & & 1 & & & & \\
\hline AA & .571 & 1 & & & & .605 & 1 & & & \\
\hline A & .300 & .550 & 1 & & & .399 & .646 & 1 & & \\
\hline BBB & .257 & .412 & .527 & 1 & & .287 & .507 & .481 & 1 & \\
\hline BBB- & .284 & .398 & .464 & .827 & 1 & .242 & .455 & .458 & .841 & 1 \\
\hline
\end{tabular}

Correlations include all vintages and ratings available. The data for each vintage uses all data available for computing the correlations across credit ratings

correlations across vintages are highest for the AAA tranches but this is not particularly surprising because they bear less idiosyncratic risk than lower-rated tranches.

Table 3 Correlations of returns across vintages within credit ratings

\begin{tabular}{|c|c|c|c|c|c|c|c|c|}
\hline Vintage & $06-1$ & $06-2$ & $07-1$ & $07-2$ & $06-1$ & $06-2$ & $07-1$ & $07-2$ \\
\hline & \multicolumn{4}{|c|}{ AAA credit rating } & \multicolumn{4}{|c|}{ AA credit rating } \\
\hline $06-1$ & 1 & & & & 1 & & & \\
\hline $06-2$ & .869 & 1 & & & .604 & 1 & & \\
\hline 07-1 & .815 & .888 & 1 & & .506 & .711 & 1 & \\
\hline \multirow[t]{2}{*}{$07-2$} & .812 & .865 & .932 & 1 & .503 & .675 & .785 & 1 \\
\hline & \multicolumn{4}{|c|}{ A credit rating } & \multicolumn{4}{|c|}{$\mathrm{BBB}$ credit rating } \\
\hline $06-1$ & 1 & & & & 1 & & & \\
\hline $06-2$ & .631 & 1 & & & .514 & 1 & & \\
\hline $07-1$ & .480 & .584 & 1 & & .461 & .601 & 1 & \\
\hline \multirow[t]{2}{*}{$07-2$} & .549 & .586 & .561 & 1 & .477 & .497 & .481 & 1 \\
\hline & \multicolumn{8}{|c|}{ BBB- credit rating } \\
\hline $06-1$ & 1 & & & & & & & \\
\hline $06-2$ & .508 & 1 & & & & & & \\
\hline 07-1 & .523 & .565 & 1 & & & & & \\
\hline $07-2$ & .432 & .418 & .471 & 1 & & & & \\
\hline
\end{tabular}

This table shows the simple correlations of returns for all available vintages and ratings for the $\mathrm{ABX}$ indices. The tables use the maximum number of observations possible to compute each correlation. For example, the correlation of the AAA tranches of the January 2006 vintage and the July 2006 vintage uses all observations for which data are available for both vintages. Similarly, the correlation of the AAA tranches of the January 2006 vintage and the January 2007 vintage uses all observations for which data are available for both vintages 


\section{Modelling Framework for ABX Data}

Financial market returns are frequently modelled with latent factor models, for example by Diebold and Nerlove (1989) and Dungey and Martin (2007). In this paper, we include four factors reflecting vintage effects in addition to the common, credit rating and idiosyncratic factors present in Longstaff and Rajan (2008). The explicit differences in ratings and vintages and the unbalanced nature of the data allow us to identify these four factors from the data rather than applying factor labels ex post. The model is

$$
y_{i, j, t}=\beta_{i, j} w_{t}+\theta_{i, j} v_{i, t}+\varphi_{i, j} k_{j, t}+\phi_{i, j} f_{i, j, t}
$$

where $y_{i, j, t}$ is the demeaned return on the $\mathrm{ABX}$ index of vintage $i$ and credit rating $j$ at time $t$. The vintage is the date of issuance of the security. The factors represent a common shock affecting all assets, $w_{t}$; a vintage shock unique to all assets of a particular index date, $v_{i, t}$; a ratings shock unique to assets of a specific rating across all vintages, $k_{j, t}$; and idiosyncratic shocks, $f_{i, j, t}$.

To capture serial correlation in the data, the common, ratings and vintage factors follow AR(1) processes. As in previous research on factor models (Dungey et al. 2000), we do not estimate persistence in the idiosyncratic shocks. The additional features of the model can be written

$$
\begin{gathered}
w_{t}=\rho_{w} w_{t-1}+\eta_{w t} \\
v_{i, t}=\rho_{v, i} v_{i, t-1}+\eta_{v, i, t} \\
k_{j, t}=\rho_{k, j} k_{j, t-1}+\eta_{k, j, t} \\
f_{i, j, t}=\eta_{i, j, t} \\
E\left(\eta_{w, t}\right)=0, E\left(\eta_{w, t} \eta_{w, s}\right)=\sigma_{w}^{2} \\
E\left(\eta_{z, t} \eta_{z, s}\right)=0 \text { for } t \neq s \text { for } z=(v, i),(k, j),(f, i, j) \\
E\left(\eta_{z, t} \eta_{a, t}\right)=0 \text { for } a, z=(v, i),(k, j),(f, i, j) \text { and } a \neq z
\end{gathered}
$$

where equations (6) to (9) indicate that the shocks to each factor are independent with constant variances. There are no other restrictions on the variance-covariance matrix of the returns. The conditional variances of the returns vary over time and we account for this feature of the data. Our state space model is already heavily parameterized and it is impractical to include ARCH estimation directly into the estimation of the factor model. Instead, we pre-filter the returns by estimating an 
Table 4 Estimates of IGARCH models

\begin{tabular}{|c|c|c|c|c|c|}
\hline \multirow[t]{2}{*}{ Estimated parameter } & \multicolumn{5}{|l|}{ Rating } \\
\hline & AAA & $\mathrm{AA}$ & $\mathrm{A}$ & BBB & BBB- \\
\hline & \multicolumn{5}{|c|}{ Vintage 06-1 } \\
\hline Constant & -0.00004 & 0.00003 & 0.00015 & -0.00154 & 0.00010 \\
\hline Standard error of constant & 0.00001 & 0.00004 & 0.00006 & 0.00052 & 0.00020 \\
\hline IGARCH term $\left(\gamma_{1}\right)$ & 0.1829 & 0.1746 & 0.1835 & 0.1873 & 0.0988 \\
\hline \multirow[t]{2}{*}{ Standard error of $\gamma_{1}$} & 0.0333 & 0.0311 & 0.0180 & 0.0455 & 0.0143 \\
\hline & \multicolumn{5}{|c|}{ Vintage $06-2$} \\
\hline Constant & -0.00042 & 0.00005 & 0.00002 & -0.00190 & 0.00037 \\
\hline Standard error of constant & 0.00064 & 0.00008 & 0.00006 & 0.00067 & 0.00118 \\
\hline IGARCH term $\left(\gamma_{1}\right)$ & 0.1438 & 0.1993 & 0.2000 & 0.1908 & 0.1029 \\
\hline \multirow[t]{2}{*}{ Standard error of $\gamma_{1}$} & 0.0565 & 0.0423 & 0.0200 & 0.0406 & 0.0235 \\
\hline & \multicolumn{5}{|c|}{ Vintage $07-1$} \\
\hline Constant & 0.00019 & 0.00018 & -0.00080 & -0.00280 & -0.00240 \\
\hline Standard error of constant & 0.00012 & 0.00017 & 0.00064 & 0.00097 & 0.00086 \\
\hline IGARCH term $\left(\gamma_{1}\right)$ & 0.1294 & 0.1650 & 0.1584 & 0.1472 & 0.1280 \\
\hline \multirow[t]{2}{*}{ Standard error of $\gamma_{1}$} & 0.0178 & 0.0330 & 0.0286 & 0.0646 & 0.0356 \\
\hline & \multicolumn{5}{|c|}{ Vintage $07-2$} \\
\hline Constant & 0.00077 & -0.00090 & -0.00218 & -0.00299 & 0.00196 \\
\hline Standard error of constant & 0.00100 & 0.00186 & 0.00149 & 0.00105 & 0.00063 \\
\hline IGARCH term $\left(\gamma_{1}\right)$ & 0.1044 & 0.0943 & 0.1370 & 0.1249 & 0.1528 \\
\hline Standard error of $\gamma_{1}$ & 0.0288 & 0.0879 & 0.0344 & 0.2062 & 0.0392 \\
\hline
\end{tabular}

The parameters are estimates of the IGARCH equations for the returns $r_{i, j, t}$

$r_{i, j, t}=a_{i, j}+h_{i, j, t} y_{i, j, t}$

$h_{i, j, t}^{2}=\gamma_{1}\left(r_{i, j, t-1}-a_{i, j}\right)^{2}+\left(1-\gamma_{1}\right) h_{i, j, t-1}^{2}$

where $h_{i, j, t}$ is the conditional standard deviation of $r_{i, j, t}$ and $y_{i, j, t}$ is the innovation in the return with zero mean and unit standard deviation. The table presents estimate parameters for all vintages and ratings

$\operatorname{IGARCH}(1,1)$ model and use the standardized returns in the factor model. ${ }^{5}$ If we let $y_{i, j, t}$ represent these standardized returns and $r_{i, j, t}$ represent the raw (unstandardized) returns, then

$$
\begin{gathered}
r_{i, j, t}=a_{i, j}+h_{i, j, t} y_{i, j, t} \\
h_{i, j, t}^{2}=\gamma_{1, i, j}\left(r_{i, j, t-1}-a_{i, j}\right)^{2}+\left(1-\gamma_{1, i, j}\right) h_{i, j, t-1}^{2} .
\end{gathered}
$$

\footnotetext{
${ }_{5}^{5}$ Prefiltering the data may result in inefficiency in the second stage of estimation. The consistency of the estimates is unaffected by two-stage estimation if the estimators are orthogonal, which seems a strong assumption in our application. We do not focus on statistical significance of parameters and our analysis of the factors uses estimates of the factors with the filtering reversed.
} 
Table 5 Summary statistics for standardized asset returns by vintage

\begin{tabular}{lllllll}
\hline Rating $\quad$ Mean & $\begin{array}{l}\text { Standard } \\
\text { deviation }\end{array}$ & Minimum & Maximum & Skewness & $\begin{array}{l}\text { Excess } \\
\text { kurtosis }\end{array}$ & $\begin{array}{l}\text { Number of } \\
\text { 7observations }\end{array}$ \\
\hline
\end{tabular}

Vintage 06-1

$\begin{array}{lrrrrrrr}\text { AAA } & -0.0876 & 1.3641 & -17.798 & 8.473 & -3.154 & 36.585 & 990 \\ \text { AA } & -0.1067 & 1.2440 & -8.002 & 8.614 & -0.390 & 8.506 & 990 \\ \text { A } & -0.1400 & 1.1693 & -5.923 & 8.292 & 0.157 & 7.038 & 990 \\ \text { BBB } & -0.1622 & 1.1564 & -7.056 & 12.827 & 0.628 & 21.347 & 990 \\ \text { BBB- } & -0.1763 & 1.1378 & -7.586 & 8.337 & -0.342 & 8.594 & 990\end{array}$

Vintage 06-2

\begin{tabular}{|c|c|c|c|c|c|c|c|}
\hline AAA & -0.0914 & 1.2205 & -14.639 & 6.579 & -3.169 & 32.124 & 865 \\
\hline $\mathrm{AA}$ & -0.1318 & 1.2739 & -7.652 & 9.679 & -0.221 & 9.370 & 865 \\
\hline A & -0.1721 & 1.2027 & -6.222 & 8.327 & -0.196 & 5.180 & 865 \\
\hline $\mathrm{BBB}$ & -0.1919 & 1.1811 & -7.203 & 10.417 & -0.083 & 12.605 & 865 \\
\hline BBB- & -0.1968 & 1.1343 & -7.596 & 8.413 & -0.188 & 10.112 & 865 \\
\hline \multicolumn{8}{|c|}{ Vintage $07-1$} \\
\hline AAA & -0.0880 & 1.1743 & -8.911 & 6.014 & -1.204 & 8.870 & 739 \\
\hline $\mathrm{AA}$ & -0.1304 & 1.2057 & -6.191 & 8.190 & -0.038 & 7.982 & 739 \\
\hline A & -0.1799 & 1.1484 & -5.534 & 7.661 & -0.130 & 4.624 & 739 \\
\hline BBB & -0.2088 & 1.1617 & -7.109 & 7.017 & -0.847 & 7.442 & 739 \\
\hline BBB- & -0.2073 & 1.1368 & -8.470 & 5.421 & -0.998 & 6.931 & 739 \\
\hline \multicolumn{8}{|c|}{ Vintage $07-2$} \\
\hline AAA & -0.0699 & 1.1123 & -7.825 & 4.898 & -1.015 & 7.171 & 613 \\
\hline $\mathrm{AA}$ & -0.1178 & 1.1359 & -5.960 & 8.358 & 0.071 & 8.795 & 613 \\
\hline A & -0.1693 & 1.1197 & -5.268 & 6.843 & -0.010 & 4.147 & 613 \\
\hline $\mathrm{BBB}$ & -0.1958 & 1.1379 & -6.832 & 6.508 & -1.024 & 8.218 & 613 \\
\hline BBB- & -0.1807 & 1.1287 & -7.404 & 6.462 & -0.535 & 7.060 & 613 \\
\hline
\end{tabular}

This table shows summary statistics for the returns standardized for the IGARCH in the raw returns. There still is skewness and excess kurtosis, although generally quite a bit less than in the raw returns

Table 4 presents the parameter estimates of the IGARCH models estimated by Quasi Maximum Likelihood for all credit ratings and vintages (Lumsdaine 1996). Table 5 presents summary statistics for the adjusted returns and Fig. 2 shows the adjusted returns. The graphs suggest that the IGARCH model has stabilized the variances relative to the variances in the original series.

The factor model can be rewritten in state-space form as

$$
\begin{gathered}
Y_{t}=Z \alpha_{t}+S \varepsilon_{t} \\
\alpha_{t+1}=Y \alpha_{t}+R u_{t}
\end{gathered}
$$

where $Y_{t}$ is the vector of the returns in each asset, $E\left[\varepsilon_{t}\right]=0, E\left[\varepsilon_{t} \varepsilon_{t}^{\prime}\right]=H, E\left[u_{t}\right]=0$, 


\section{Returns Adjusted for IGARCH}

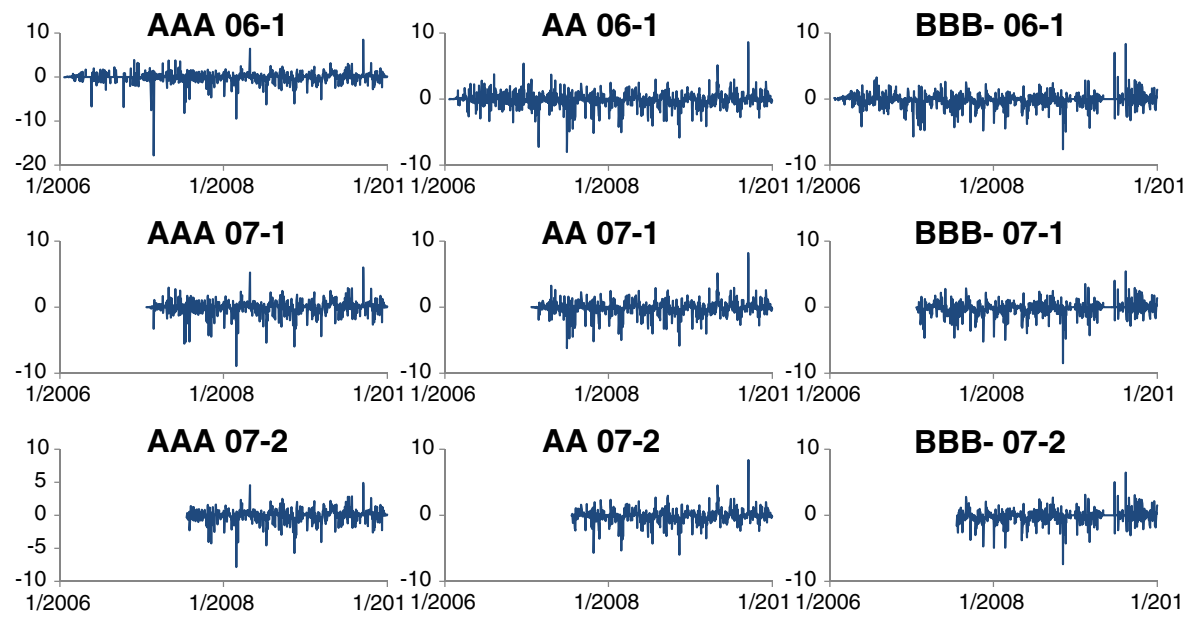

Fig. 2 Returns adjusted for IGARCH. These are the returns adjusted for $\operatorname{IGARCH}(1,1)$ based on the estimates in Table 4. The "06-1" vintage is the January 2006 vintage; the "07-1" vintage is the January vintage; the "07-2" vintage is the July 2007 vintage. The seemingly near-zero variances are periods of relatively low volatility

and $E\left[u_{t} u_{t}^{\prime}\right]=Q$. The evolving latent factors are contained in the vector $\alpha_{t}$ and the idiosyncratic factors, $f_{i, j, t}$ are contained in the vector $\varepsilon_{t}$.

To reduce the dimensionality of the estimation problem and keep it tractable, our empirical estimation is based on a system of nine asset returns selected to span the range of ratings and vintages. We examine AAA, AA and BBB- rated securities from the January 2006, January 2007 and July 2007 vintages. The AAA and AA tranches have the largest share of the value of underlying subprime-mortgage bonds, and the BBB- tranche is included because it is the lowest rated tranche. We include the January 2006 and July 2007 vintages because they are the first and last issuances available. We prefer the January 2007 vintage to the July 2006 vintage mainly because the January 2007 vintage is based on later mortgages. These mortgages may have been less carefully vetted when created and may be affected more by the decline in housing prices and mortgages subsequently becoming upside down.

The following definitions of $Z$ and $\alpha_{t}$ show the form of the restrictions in the model,

$$
Z=\left[\begin{array}{ccccccc}
\beta_{1, A A A} & \theta_{1, A A A} & 0 & 0 & \varphi_{1, A A A} & 0 & 0 \\
\beta_{1, A A} & \theta_{1, A A} & 0 & 0 & 0 & \varphi_{1, A A} & 0 \\
\beta_{1, B B B} & \theta_{1, B B B} & 0 & 0 & 0 & 0 & \varphi_{1, B B B} \\
\beta_{2, A A A} & 0 & \theta_{2, A A A} & 0 & \varphi_{2, A A A} & 0 & 0 \\
\beta_{2, A A} & 0 & \theta_{2, A A} & 0 & 0 & \varphi_{2, A A} & 0 \\
\beta_{2, B B B} & 0 & \theta_{2, B B B} & 0 & 0 & 0 & \varphi_{2, B B B} \\
\beta_{3, A A A} & 0 & 0 & \theta_{3, A A A} & \varphi_{3, A A A} & 0 & 0 \\
\beta_{3, A A} & 0 & 0 & \theta_{3, A A} & 0 & \varphi_{3, A A} & 0 \\
\beta_{3, B B B} & 0 & 0 & \theta_{3, B B B} & 0 & 0 & \varphi_{3, B B B}
\end{array}\right]
$$




$$
\alpha_{t}=\left[\begin{array}{c}
w_{t} \\
v_{1, t} \\
v_{2, t} \\
v_{3, t} \\
k_{A A A, t} \\
k_{A A, t} \\
k_{B B B, t}
\end{array}\right]
$$

Defining $\Upsilon$ as a $7 \times 7$ diagonal matrix of autoregressive parameters, $\rho=\left[\rho_{w} \rho_{v, i} \rho_{k, j}\right]$ for all $i, j ; S_{t}$ as a $9 \times 9$ matrix with parameters $\varphi_{i, j}$ on the main diagonal; and $R$ as the appropriately sized identity matrix where the factor variances are standardized to unity, we can estimate the parameters by the standard Kalman filter procedure. ${ }^{6}$ Its prediction equations are given by

$$
\begin{gathered}
\alpha_{t+1}=\Upsilon \alpha_{t \mid t} \\
P_{t+1 \mid t}=\Upsilon P_{t \mid t} \Upsilon^{\prime}+S Q S^{\prime}
\end{gathered}
$$

where $P_{t+1 \mid t}$ is the prediction vector. The updating equations are

$$
\begin{gathered}
\alpha_{t \mid t}=\alpha_{t}+P_{t} Z^{\prime} F_{t}^{-1} v_{t} \\
P_{t \mid t}=P_{t}-P_{t} Z^{\prime} F_{t}^{-1} Z P_{t}^{\prime}
\end{gathered}
$$

Where

$$
\begin{gathered}
v_{t}=Y_{t}-Z \alpha_{t} \\
F_{t}=Z P_{t} Z^{\prime}+Z
\end{gathered}
$$

Furthermore, we accommodate the unbalanced nature of our data by constructing a dummy matrix, $D_{t}$, as follows

$$
D_{t}=\left[\begin{array}{ccccccc}
1 & 1 & 0 & 0 & 1 & 0 & 0 \\
1 & 1 & 0 & 0 & 0 & 1 & 0 \\
1 & 1 & 0 & 0 & 0 & 0 & 1 \\
d_{1 t} & 0 & d_{1 t} & 0 & d_{1 t} & 0 & 0 \\
d_{1 t} & 0 & d_{1 t} & 0 & 0 & d_{1 t} & 0 \\
d_{1 t} & 0 & d_{1 t} & 0 & 0 & 0 & d_{1 t} \\
d_{2 t} & 0 & 0 & d_{2 t} & d_{2 t} & 0 & 0 \\
d_{2 t} & 0 & 0 & d_{2 t} & 0 & d_{2 t} & 0 \\
d_{2 t} & 0 & 0 & d_{2 t} & 0 & 0 & d_{2 t}
\end{array}\right]
$$

\footnotetext{
${ }^{6}$ Starting values are taken as the consistent estimates of the parameters of the factor model in equation (1) obtained from unconditional moments using GMM.
} 
where $d_{1 t}$ takes the value of 1 from the initiation of the $07-1$ vintage onwards and 0 otherwise and $d_{2 t}$ is similarly defined with respect to the vintage 07-2. The Kalman filter equations are then modified by replacing $Z$ with $Z \circ D_{t}$ wherever it appears in the filter with the operator 。 indicating element-by-element multiplication.

\section{Results}

A preliminary yet informative way to analyze the results is to perform an unconditional variance decomposition using equation (1) which implies

$$
\operatorname{Var}\left(y_{i, j}\right)=\beta_{i, j}^{2} \operatorname{Var}(w)+\theta_{i, j}^{2} \operatorname{Var}\left(v_{i}\right)+\varphi_{i, j}^{2} \operatorname{Var}\left(k_{j}\right)+\phi_{i, j}^{2} \operatorname{Var}\left(f_{i, j}\right)
$$

so that, for example, the contribution of the vintage factor to variance in asset $y_{i, j}$ is expressed as

$$
\frac{\theta_{i, j}^{2} \operatorname{Var}\left(v_{i}\right)}{\beta_{i, j}^{2} \operatorname{Var}(w)+\theta_{i, j}^{2} \operatorname{Var}\left(v_{i}\right)+\varphi_{i, j}^{2} \operatorname{Var}\left(k_{j}\right)+\phi_{i, j}^{2} \operatorname{Var}\left(f_{i, j}\right)}
$$

and similarly for other contributing factors.

Table 6 presents the unconditional variance decomposition for the full period of each vintage and for selected subperiods. ${ }^{7}$ For the full period, the common factor is most important for the AAA and AA ratings for all vintages. Variability of the BBBtranches is less closely related to the common factor and more closely related to the rating factor. The vintage factors are relatively unimportant for all assets. The ratings factors, on the other hand, affect all of the vintages and credit ratings, although they are less important for the AA tranches of the January and July 2007 vintages. The importance of idiosyncratic factors differs across vintages and across ratings. In particular, they exert a stronger influence on later vintages and we also observe an upward drift in terms of ratings over time. This likely reflects the losses and consequent collapse in prices for the lower-rated tranches of the later vintages, which decimated the protection for the higher-rated tranches. As a result of the large losses, idiosyncratic losses on mortgages migrate up to the AA and even the AAA tranches.

Table 6 also presents the unconditional variance decompositions for subperiods. In the non-crisis period of 2006, the variances of the AAA and AA tranches are dominated by the common factor and the credit rating factors. The idiosyncratic factor is easily the most important factor for the BBB- tranche and is quite unimportant for the higher-rated tranches. This is consistent with the role of the BBB- tranche as the absorber of the relatively small idiosyncratic losses. The common shock accounts for about half the variance of the AAA and AA tranches. This contrasts with Longstaff and Rajan's (2008) finding that a common factor is relatively unimportant in non-crisis periods. The first half of 2007 does not look markedly different for these securities. There are however differences in the relative importance of the factors for the January 2007 vintage. The AAA securities look little different, but the

\footnotetext{
$\overline{7}$ The parameter values themselves are estimated consistently, but are not very informative by themselves. The parameter values are available from the authors upon request.
} 
Table 6 Average contribution of factors to variance in returns for subperiods

\begin{tabular}{|c|c|c|c|c|c|c|c|c|c|}
\hline \multirow[t]{2}{*}{ Factor/Vintage And rating } & \multicolumn{3}{|c|}{ January 2006} & \multicolumn{3}{|c|}{ January 2007} & \multicolumn{3}{|c|}{ July 2007} \\
\hline & AAA & AA & BBB- & AAA & AA & BBB- & AAA & AA & BBB- \\
\hline & \multicolumn{9}{|c|}{ Start of each vintage to December 2009} \\
\hline Common & .49 & .62 & .24 & .58 & .32 & .29 & .55 & .47 & .32 \\
\hline Vintage & .05 & .02 & .01 & .00 & .00 & .00 & .00 & .00 & .00 \\
\hline Credit rating & .43 & .35 & .39 & .40 & .11 & .52 & .33 & .15 & .63 \\
\hline \multirow[t]{2}{*}{ Idiosyncratic } & .03 & .01 & .37 & .03 & .57 & .19 & .38 & .38 & .05 \\
\hline & \multicolumn{9}{|c|}{ January 2006 to December 2006} \\
\hline Common & .43 & .50 & .21 & & & & & & \\
\hline Vintage & .08 & .03 & .00 & & & & & & \\
\hline Credit rating & .45 & .46 & .29 & & & & & & \\
\hline \multirow[t]{2}{*}{ Idiosyncratic } & .03 & .01 & .50 & & & & & & \\
\hline & \multicolumn{6}{|c|}{ January 2007 to June 2007} & & & \\
\hline Common & .37 & .50 & .18 & .47 & .30 & .24 & & & \\
\hline Vintage & .13 & .09 & .00 & .00 & .00 & .00 & & & \\
\hline Credit rating & .46 & .40 & .41 & .50 & .22 & .57 & & & \\
\hline \multirow[t]{2}{*}{ Idiosyncratic } & .04 & .01 & .41 & .03 & .48 & .19 & & & \\
\hline & \multicolumn{9}{|c|}{ July 2007 to December 2008} \\
\hline Common & .53 & .71 & .26 & .59 & .32 & .30 & .55 & .46 & .33 \\
\hline Vintage & .02 & .01 & .00 & .00 & .00 & .00 & .00 & .00 & .00 \\
\hline Credit rating & .42 & .28 & .43 & .38 & .08 & .51 & .33 & .14 & .62 \\
\hline \multirow[t]{2}{*}{ Idiosyncratic } & .03 & .00 & .32 & .03 & .60 & .19 & .12 & .41 & .05 \\
\hline & \multicolumn{9}{|c|}{ January 2009 to December 2009} \\
\hline Common & .57 & .70 & .27 & .62 & .34 & .30 & .58 & .48 & .32 \\
\hline Vintage & .02 & .01 & .00 & .00 & .00 & .00 & .00 & .00 & .00 \\
\hline Credit rating & .39 & .29 & .45 & .35 & .10 & .53 & .31 & .16 & .64 \\
\hline Idiosyncratic & .02 & .00 & .28 & .02 & .56 & .17 & .11 & .36 & .04 \\
\hline
\end{tabular}

The first panel of the table shows the variance decompositions for each of the vintages from the inception of each vintage until the end of 2009. The second panel shows the variance decompositions for a period clearly before the financial crisis, 2006. The second panel shows the variance decomposition for the first half of 2007. The third panel shows the variance decomposition for the period most evidently one of financial crisis and the fourth panel shows developments in 2009

idiosyncratic factor becomes quite a bit more important for the AA securities, roughly the same as for the BBB- tranche of the January 2006 vintage.

In the crisis from July 2007 to the end of 2008, the relative contributions of the factors change markedly. The common factor is most important for the AAA-rated tranches of all vintages. For the BBB- tranches, idiosyncratic factors remain prominent although the common factor exerts more influence and the ratings factors assume most importance. Idiosyncratic factors remain most important for the BBBtranche in the January 2006 vintage, though, as well as for the AA tranches of the January and July 2007 vintages. Vintage factors, never especially important, all but disappear. 
In 2009, there is little evidence of any return to pre-crisis factor contributions. The variance decompositions are hard to distinguish from those of the crisis period. This analysis reveals substantial time variation in the relative factor contributions to ABX returns.

Figure 3 shows daily variance decompositions for each vintage and credit rating. Each panel has 3 columns, representing AAA, AA and BBB- rated assets respectively. The first row in each panel presents the observed asset return volatility, and the following rows present the contributions of each factor to that volatility. Note that the common factor, shown in the second row, tends to be more important for the higherrated tranches and the idiosyncratic factor tends to be more important for lower-rated assets. It is important to note that this is the variance decomposition for the standardized returns, not the raw returns. We discuss each of the factors in turn before delving more deeply into the relationship between the common factor with observables.

\subsection{The Common Factor}

The second row of Fig. 3 shows the common factor becoming increasingly important over time compared with other factors. Its influence is negligible during the relatively tranquil conditions that characterized the financial system before early 2007. This is consistent with relatively low default correlations during this period and the low credit default spreads demanded for protection against default of the pooled assets. For example, the spread for the AAA tranche of the first vintage was a mere 18 basis points, falling to $9 \mathrm{bps}$ for the January 2007 vintage and finally increasing to $76 \mathrm{bps}$ for the last vintage. The low realization of the common shock in the early period compared to the crisis period contributed to claims that credit rating agencies, and some market participants, under-estimated risk. Brennan et al. (2009) show that if investors rely exclusively on rating agencies to accurately assess creditworthiness, this can lead to mispricing of CDOs' (and similar products') tranches. ${ }^{8}$

As the crisis emerges in mid-2007, the contribution of the common shock to asset volatility increases noticeably. Its pervasive nature affects all assets in the underlying pool and thus heightens their pairwise correlations. These increased levels of comovement quickly eroded the buffer protecting the AAA tranche and in relative terms implies investors in these assets were worst hit by the common shock. This is consistent with the argument of Coval et al. (2009) that an amplified common shock effectively transfers risk from lower to more senior tranches. From mid-2007 onwards, the common factor swamps all other factors, suggesting that all AAA-rated assets behaved increasingly alike without any distinguishing vintage effects.

A number of other studies document a similar pattern for systematic shocks in different asset markets. Eichengreen et al. (2009) analyze CDS spreads of 45 international financial institutions and document an increasing role for a common factor as the financial crisis evolves, with its largest influence in the aftermath of the Lehman collapse. Similarly, Longstaff and Myers (2009) show that a common factor can explain a substantial proportion of bank and CDO equity return variation.

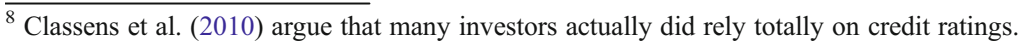


Fig. 3 Variance decomposition. This figure shows the daily variance decomposition for each vintage and credit rating within each vintage. The first row of each panel shows squared standardized returns. The following rows in the panel show the contributions by the common factor, the corresponding vintage factor, the corresponding ratings factor and the idiosyncratic factor. The vertical scales of the graphs differ vertically but not horizontally. The vertical scales differ too much to use the same scale for all graphs. Comparisons across credit ratings within a vintage are simpler with the same scale for all three credit ratings a
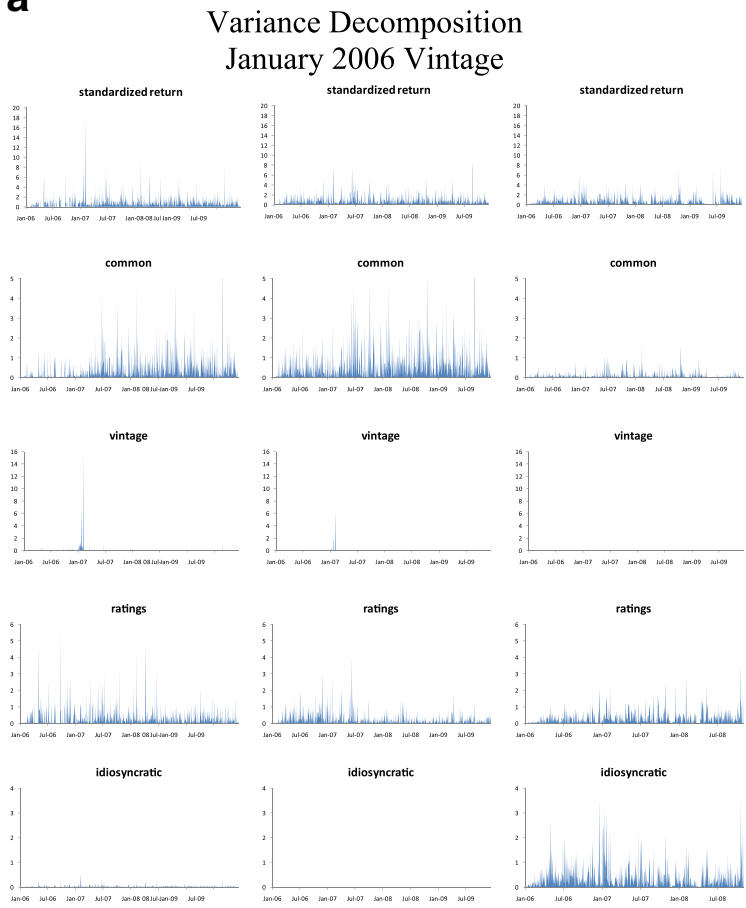

b

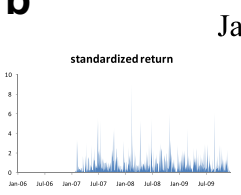

January 2007 Vintage
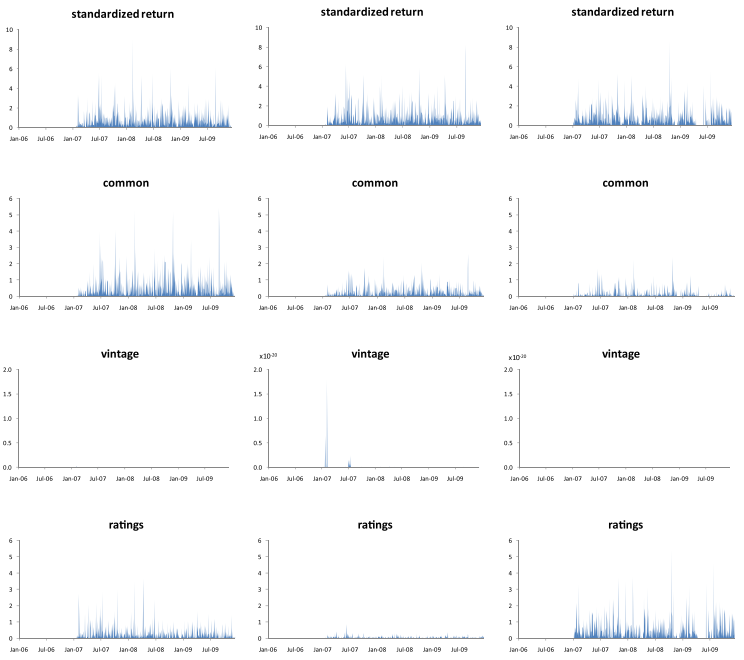

idiosyncratic

idiosyncratic

idiosyncratic
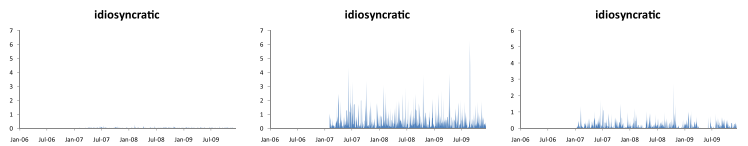
Fig. 3 (continued)

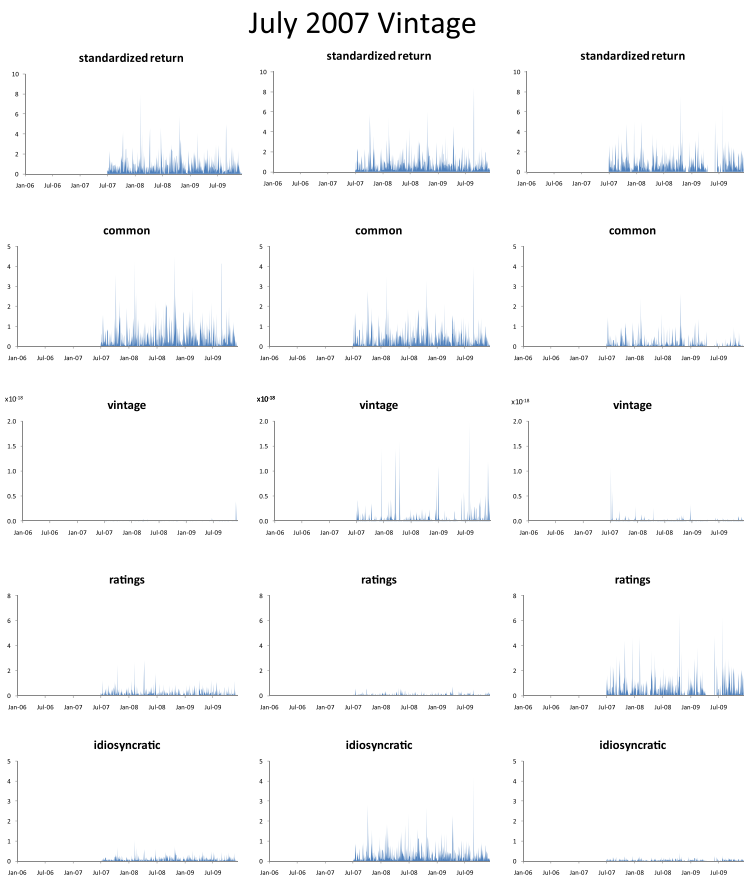

\subsection{Ratings and Vintage Factors}

Both the rating and vintage factors exert a time-varying influence on asset return variability. At various times, the specific rating and vintage helped to differentiate between assets. For the earliest vintage, 06-1, ratings matter and this factor accounts for a non-trivial amount of asset return variability. For later vintages, ratings matter little for the two most senior tranches but continue to be an important determinant of returns for the equity tranche. In relative terms the contribution of the vintage factor is the smallest of all factors. However, in early 2007 as ABS markets become unsettled, the vintage factor has a pronounced effect. This suggests that market participants began to distinguish between $\mathrm{ABX}$ indices on the basis of the underlying asset quality. For all tranches the largest impact of the vintage factor occurs for the July 2007 issuance. The deals underlying this issue were struck in the first half of 2007 , when US house price declines were already evident (previous issues were based on rising and then peak house prices).

The rating and vintage factors play an important role in distinguishing assets during non-crisis periods. However, during crisis, their influence is swamped by the common and idiosyncratic components.

\subsection{The Idiosyncratic Factor}

Just as the common factor exerts its greatest influence on the most senior claim, idiosyncratic shocks have their greatest effect at the other end of the rating spectrum. In the earliest vintage, idiosyncratic risk almost exclusively affects the BBB- tranche 
and were of little concern to holders of more senior claims because the lower-rated tranches absorbed these risks. In later vintages, there is a greater role for idiosyncratic shocks as mezzanine tranches also exhibit some vulnerability to them, most likely due to the inadequacy of the equity tranches to protect them. Interestingly, idiosyncratic shocks fall in importance for BBB- rated assets, which may be due to overwhelming influence of the common shock or may also reflect a lack of trades when the value of the BBB- tranche flattened out near zero. ${ }^{9}$

The behaviour of the idiosyncratic shock is consistent with the arguments outlined earlier. In normal market conditions, when assets in the underlying pool exhibited relatively low correlation, idiosyncratic risk resulted in a few random subprime mortgage defaults whose effects were absorbed by the equity tranche or other lower-rated tranches. The onset of the crisis in July 2007 led to this risk source being swamped by the common shock, limiting its impact on asset return volatility.

\section{What Drives the Common Factor?}

Initially, we recover the level of the common factor. The logarithm of the value of the underlying asset, $p_{i, j, t}$, for vintage $i$, credit rating $j$, in period $t$, from the adjusted return, $y_{i, j, t}$, accounting for $\mathrm{GARCH}$ is

$$
p_{i, j, t}=a+h_{i, j, t} y_{i, j, t}+p_{i, j, t-1}
$$

by the definition of the return and the equation for conditional heteroskedasticity (10). The relationship between this index value and the factors can be seen by substituting for $y_{i, j, t}$ to write

$$
p_{i, j, t}=a+h_{i, j, t}\left(\beta_{i, j} w_{t}+\theta_{i, j} v_{i, t}+\varphi_{i, j} k_{j, t}+\phi_{i, j} f_{i, j, t}\right)+p_{i, j, t-1}
$$

The contribution of the factors to the value of the assets can then be written as

$$
p_{i, j, t}=a+\beta_{i, j} h_{i, j, t} w_{t}+\theta_{i, j} h_{i, j, t} v_{i, t}+\varphi_{i, j} h_{i, j, t} k_{j, t}+\phi_{i, j} h_{i, j, t} f_{i, j, t}+p_{i, j, t-1}
$$

where $\beta_{i, j} h_{i, j, t} w_{t}$ is the contribution of the common factor to the value of the asset with vintage $i$ and rating $j$ in period $t$. Note that the common factor including heteroskedasticity is different for each tranche and vintage because different conditional standard deviations translate the adjusted returns into raw returns.

Section 4 showed that the common factor plays a major part in changes to the values of the most senior tranches of subprime-mortgage backed assets. We focus the rest of our analysis on the drivers of the common factor. We use the AAA tranche of the 06-1 vintage to construct the level of the common factor $h_{i, j, t} w_{t}$ because it represents the highest valued CDO tranche for the longest period. ${ }^{10}$ Fig. 4 shows the integrated common factor with its level set to

\footnotetext{
${ }^{9}$ The buyer of insurance in the CDS on the CDO makes an initial payment to the insurance seller equal to the difference between 100 and the index value. When the index is near zero, this becomes a substantial unsecured loan.

${ }^{10}$ For example, $\mathrm{Hu}$ (2007) reports that for CDOs issued in 2006, AAA-rated assets accounted for $85 \%$ of dollar value and $36 \%$ of the number of tranches, while the figures for Baa and lower rated assets were $3.7 \%$ and $24 \%$ respectively. Many deals had more than one AAA tranche. The ABX index is based on the most subordinate AAA tranche.
} 


\section{The Integrated Common Factor}

Integrated Common Factor

AAA Tranche of 2006-1 Vintage

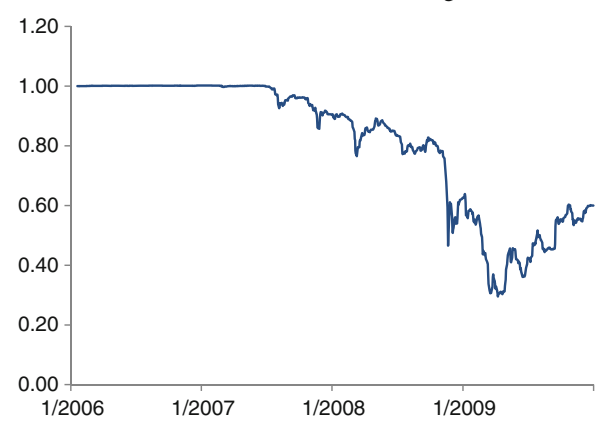

ABX Index Value AAA Tranche of 2006-1 vintage

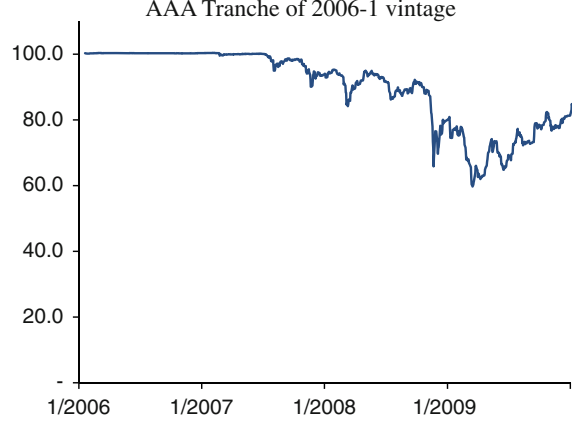

Fig. 4 The integrated common factor. The left panel shows the integrated common factor for the January 2006 AAA vintage with the initial value normalized to 1 . This value reflects the conditionally heteroskedastic behavior of the common factor derived from the conditional heteroskedasticity in the original returns. The right panel shows the actual value of the AAA tranche of the January 2006 vintage of the ABX index. Many common features appear in both figures

unity at the start of the series. ${ }^{11}$ The evolution of the common factor can be usefully compared to that of the AAA tranche of the ABX index for January 2006, both of which are shown in Fig. 4 for convenience. Consistent with the common factor's substantial importance in the evolution of the AAA tranches, the common factor reflects many of the characteristics of the AAA tranche.

Observable economic variables potentially related to the deterioration of the ABX are real estate prices, general financial market volatility and liquidity and counterparty risk. We use the logarithm of a daily price index for the U.S. real estate trusts (REITs) represented by the Dow Jones Equity All REIT Index to reflect news about housing prices; and the logarithm of the VIX index as a measure of general financial market volatility.

Liquidity and counterparty default risk are measured by three one-month interest rate spreads: the spread between the London Interbank Borrowing Rate (LIBOR) and the overnight index swap rate (OIS), LIBOR-OIS; the spread between LIBOR and the U.S. Treasury Bill rate, the TED spread; and the spread between the commercial paper rate and the U.S. Treasury Bill rate, CPR-TB.

LIBOR-OIS can be viewed as reflecting counterparty risk from the standpoint of a lender to another institution. Borrowers who believe the market is overstating their risk may also view this spread as reflecting liquidity. The TED spread is another common measure of liquidity and counterparty risk and would be partly redundant with the inclusion of LIBOR-OIS. The spread between OIS and the Treasury Bill rate (OIS-TB), which excludes the part of the TED spread already represented by LIBOROIS, provides a straightforward means of examining the informativeness of one spread relative to the other. OIS-TB is the clearest indicator of liquidity issues

\footnotetext{
${ }^{11}$ The contribution of the common factor to the measured return on the ABX is the common factor times its coefficient of 0.83. The contribution of the level of the factor to the level of ABX though depends on an unobserved initializing constant for the level of the common factor which cannot be recovered from first difference alone.
} 

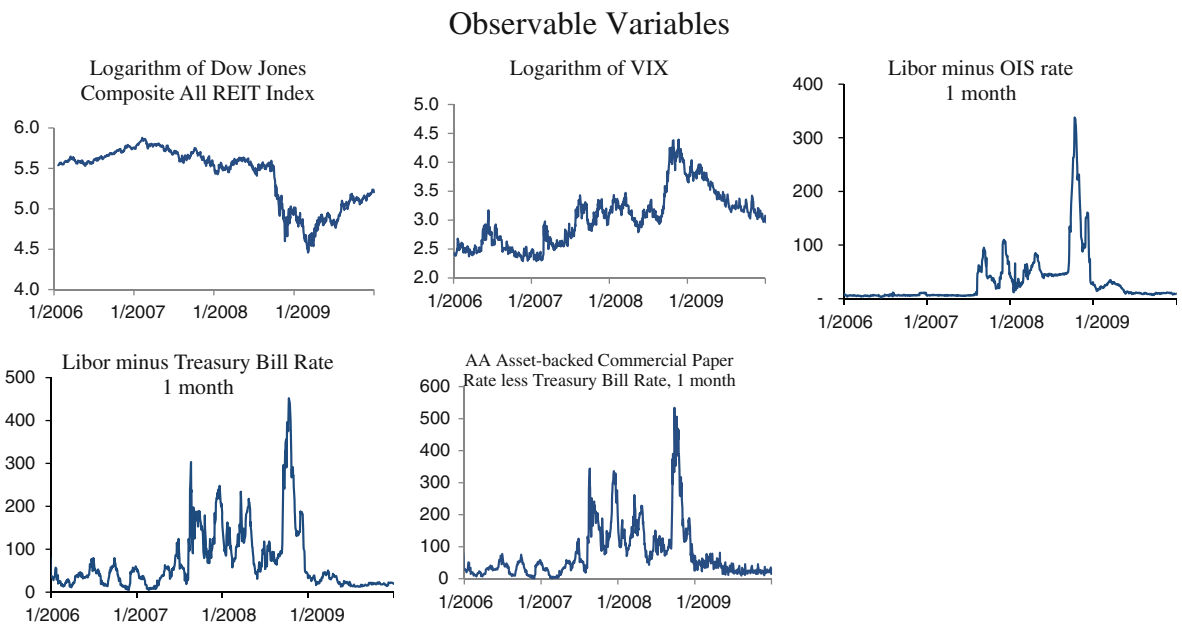

Fig. 5 Observable variables. This figure shows the values of the variables other than the ABX index which are included in the analysis of the variables' relationships. The figures suggest that the Dow-Jones Equity All REIT index and VIX have slow moving components, possibly unit roots, while the spreads do not. By the end of 2009 , the spreads return to values similar to those before the crisis, although the behavior is not identical

because the OIS rate is the rate for almost fully collateralized private transactions and the Treasury Bill rate is a nominal risk-free rate. We also include the spread between the commercial paper rate on AA-rated asset-backed commercial paper and the U.S. Treasury bill rate, which can be interpreted as reflecting flights to quality during the crisis due to concerns about the value of the underlying assets.

Figure 5 shows the observable factors. The figures clearly show evidence of episodes with increasing and then decreasing spreads, most evidently for the CPRTB spread but also for the spread of LIBOR over OIS.

Unit root tests indicate one unit root in each of the common factor, REIT and VIX. This unexpected outcome for the VIX is consistent with the results reported by Zhang

Table 7 Cointegration tests and cointegrating vector

\section{Cointegration rank tests}

Number of cointegrating Eigenvalue Trace statistic $p$-value vectors

None

At most 1

At most 2

Cointegration vector

$\begin{array}{ll}\text { Variable } & \begin{array}{l}\text { Level of } \\ \text { Common factor }\end{array} \\ \text { Coefficient } & 1 \\ \text { Standard Error } & \end{array}$

$$
0.0423
$$$$
0.0132
$$$$
57.768
$$$$
<10^{-4}
$$$$
15.841
$$$$
0.1819
$$$$
2.9071
$$$$
0.5982
$$

Maximum eigenvalue $p$-value statistic

$\begin{array}{rr}41.927 & <10^{-4} \\ 12.934 & 0.1381 \\ 2.907 & 0.5982\end{array}$

The $p$-values are based on MacKinnon, Haug and Michelis (1999). The trace test and maximum eigenvalue test lead to the same conclusion: one cointegrating vector among the three variables 
et al. (2010) for options prices. Johansen cointegration tests, reported in Table 7, are consistent with one cointegrating vector between the common factor and the logarithms of the Dow-Jones REIT index and VIX.

Table 8 presents a 3-variable Vector Error Correction Mechanism (VECM) for the common factor, the logarithm of the REIT index and the logarithm of VIX. All equations include two lags of all variables. ${ }^{12}$ One month interest-rate spreads for LIBOR-OIS, OIS-TB, and CPR-TB are included as exogenous variables. The errors are specified as a diagonal $\operatorname{GARCH}(1,1)$, estimated using a diagonal vech structure. The zero restrictions on errors across variables reduce the number of parameters estimated. $^{13}$

Table 9 presents tests to restrict this set of equations by deleting spreads. The results clearly indicate that LIBOR-OIS is very informative for these variables. The results also clearly indicate that the CPR-TB is not informative and can be dropped at little cost. The OIS-TB spread is somewhat informative, with a p-value of $10.3 \%$ for dropping it from the equations with both other spreads but a $p$-value of only $20.5 \%$ when the commercial paper rate spread is not included in the equations. Overall, the results are consistent with the informativeness of the spread of LIBOR - OIS but not the other spreads. Table 10 presents the estimated three-equation VECM with LIBOR-OIS as the only spread. While t-ratios might suggest that LIBOR-OIS is not uniformly important, likelihood ratio tests indicate that each of the variables reflects movements in LIBOR-OIS. ${ }^{14}$

The estimates in Table 10 can be used as the basis for comparing actual events with events estimated without the behaviour of LIBOR-OIS reflecting the financial crisis. We infer the no-financial-turmoil behaviour of LIBOR-OIS from its behaviour prior to the financial crisis. It is relatively simple to date the financial crisis in terms of LIBOR-OIS. It spiked from 9.65 basis points on August 8, 2007 to 38.18 basis points on August 9. This spike is extraordinary and not a random date. On August 9, 2007, BNP Paribus suspended redemptions in three funds holding securities based on subprime mortgages. Later that day, the European Central Bank and the Federal Reserve dramatically increased repurchase agreements with banks to provide additional reserves to banks. From the inception of the ABX indices on January 19, 2006 to August 8,2007 , the mean LIBOR-OIS spread is 6.32 basis points with a standard deviation of 1.38 basis points. The maximum spread is 11.95 basis points. For the rest of our time period, the mean spread is 64.38 basis points with a standard deviation of 58.88 basis points; the maximum spread is 337.75 basis points on October 10, 2008. As Fig. 5 shows, the LIBOR-OIS spread decreased from these extraordinary values. From June 1, 2009 to the end of 2009, the mean spread is 9.87 basis points with a standard deviation of 1.16 basis points, with a maximum of 12.95 basis points in

\footnotetext{
12 The choice of lag length is based on F-tests and Akaike Information Criterion values, reported in Table 9, which support the reduction from 3 to 2 lags but not further. We also examined evidence for a VECM where spreads are treated as exogenous. For LIBOR less OIS in a four-equation system, the p-value is $13.4 \%$. For LIBOR less OIS in a five-equation system, the p-value is $13.7 \%$. These systems involve many parameters, so these results are at best indicative. Attempts to estimate a six-variable system with the AA asset-backed commercial paper rate were not successful.

${ }^{13}$ Bauwens et al. (2006) and Silvennoinen and Teräsvirta (2008) review multivariate GARCH models.

14 The $p$-values for deleting the current and two lagged values of LIBOR-OIS are $0.01 \%, 4.30 \%$, and $0.02 \%$ for the common factor, the logarithm of the REIT index and for the logarithm of VIX equations respectively.
} 


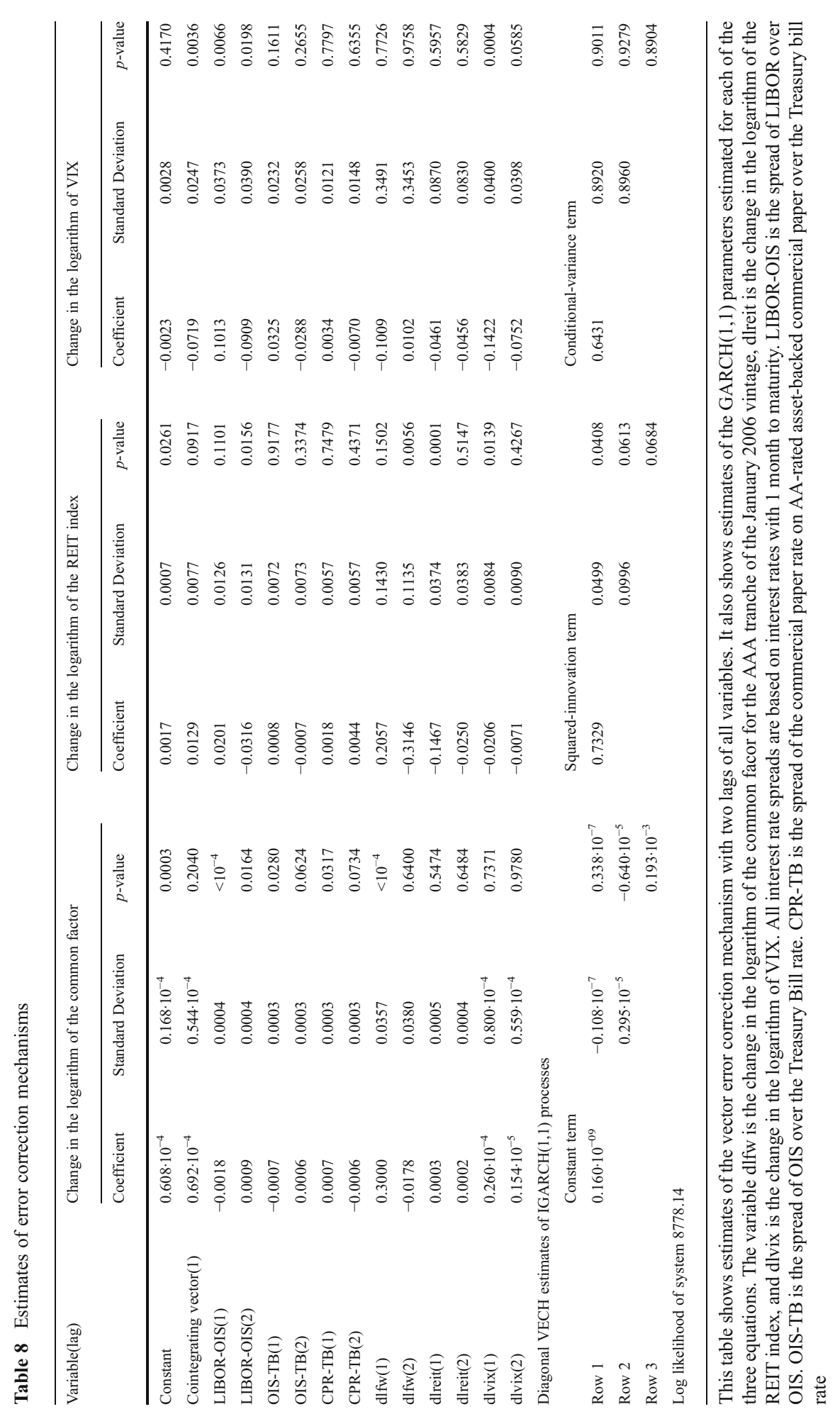


Table 9 Likelihood ratio tests of restrictions on error correction mechanism

\begin{tabular}{|c|c|c|c|}
\hline Test & Test statistic & Degrees of freedom & $p$-value \\
\hline \multicolumn{4}{|l|}{ Lag Length } \\
\hline 2 lags to 1 lag & 32.118 & 18 & 0.0213 \\
\hline 3 lags to 2 lags & 11.906 & 18 & 0.8520 \\
\hline \multicolumn{4}{|c|}{ Conditional on other spreads in equations } \\
\hline Drop Libor-OIS & 40.292 & 6 & $<10^{-4}$ \\
\hline Drop Libor-TB & 10.568 & 6 & 0.1027 \\
\hline Drop CPR-TB & 6.735 & 6 & 0.3461 \\
\hline \multicolumn{4}{|c|}{ Conditional on CPR-TB not in equations } \\
\hline Drop Libor-OIS & 34.776 & 6 & $<10^{-4}$ \\
\hline Drop Libor-TB & 8.478 & 6 & 0.2051 \\
\hline \multicolumn{4}{|c|}{ Conditional on CPR-TB and OIS-TB not in equations } \\
\hline Drop Libor-OIS & 37.318 & 12 & 0.0002 \\
\hline \multicolumn{4}{|c|}{ Current Libor-OIS helps to predict all three variables } \\
\hline 3-variable system & 14.876 & 3 & 0.0019 \\
\hline
\end{tabular}

In addition to the 3 underlying variables in the cointegrating vector error-correction mechanism - the common factor, the reit stock price index and VIX - the variables included are Libor minus the overnight index swap (OIS) rate, Libor minus the Treasury Bill rate (which can be represented by OIS minus the Treasury Bill rate if Libor-OIS is included in the equations) and the AA commercial paper rate minus the Treasury Bill rate. The tests for lag length are based on estimates of the VECM with lagged values of the three spreads. The Akaike Information Criterion values are $-17.9322,-17.9386$ and -17.9241 for lag lengths of three, two and one, leading to a choice of the same lag length as F-ratios. The last test examines whether current values of Libor-OIS included in each of the three equations in the 3-variable ECM help to predict the three variables

these 7 months. Even this slightly elevated level of LIBOR-OIS may well be a reflection of the financial crisis.

While there always is variation in LIBOR-OIS, we simplify our simulation by setting LIBOR-OIS to its average value before the financial crisis and impose that value for the crisis period. We then simulate the behaviour of the common factor, REIT and VIX using the same innovations to those three variables as derived from the estimates in Table 10. If LIBOR-OIS were exactly the same as its historical values, the actual values of the common factor, the REIT index and VIX would occur. The simulation is 'dynamic' in the sense that values of the common factor, the REIT index and VIX persist into subsequent periods, so that deviations of simulated from actual values persist. The estimated VECM, of course, will predict adjustment of the three variables in the cointegrating vector back to the stable long-run relationship. This need not mean adjustment of the levels of the variables back to their values before the financial crisis.

Figure 6 shows the actual and simulated values of the common factor, the REIT index and VIX. By the end of 2009, all of the variables still show effects of the financial crisis as reflected in LIBOR-OIS. None of the variables has returned to values similar to their values before the financial crisis. The percentage deviations between the actual values of the series - the common factor, the REIT stock price index and VIX are shown in Fig. 7. The deviations are substantial. At the end of 2009, the simulation 


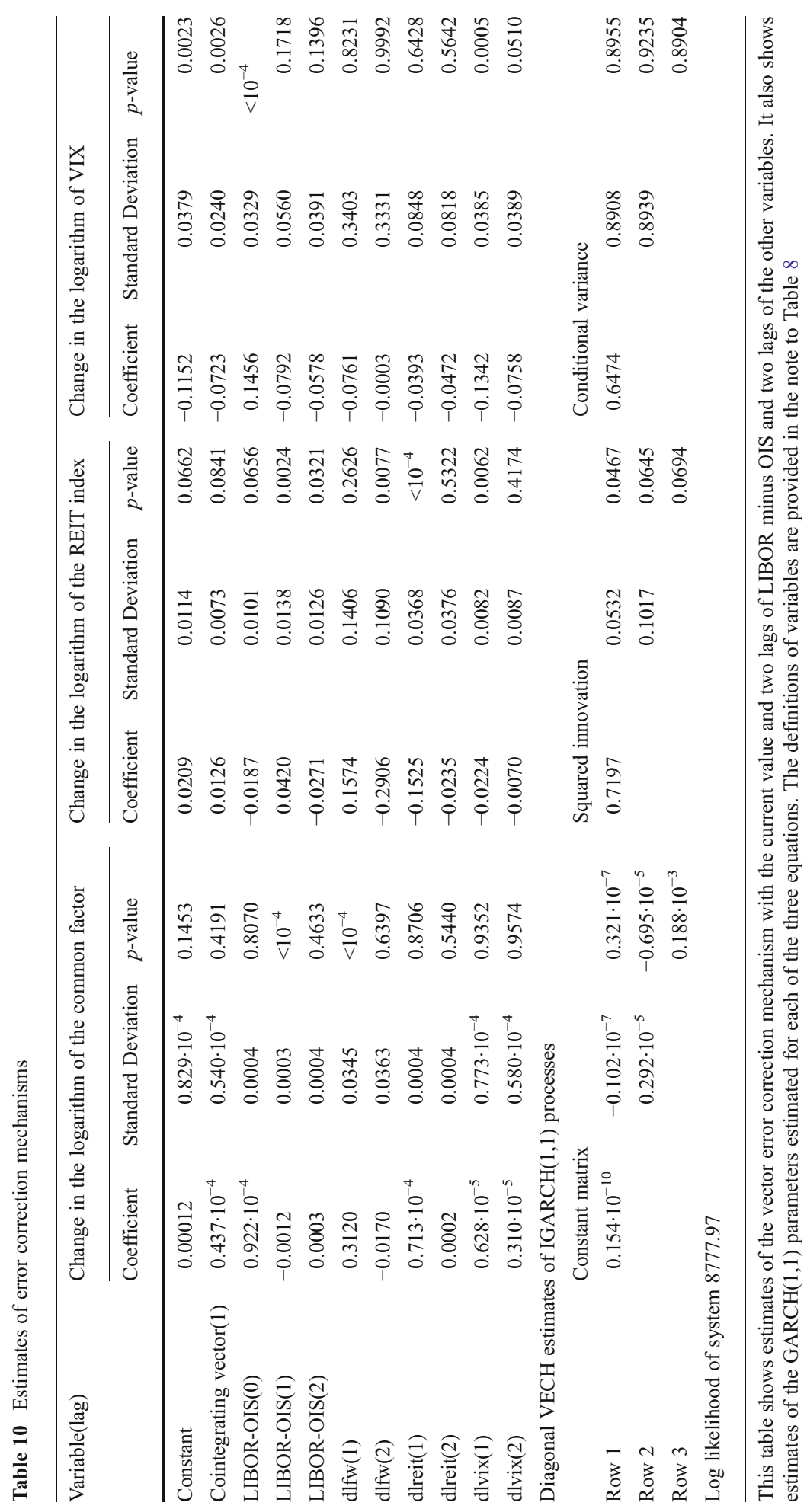


Actual and Simulated Values

Of the Common Factor, REIT Index and VIX
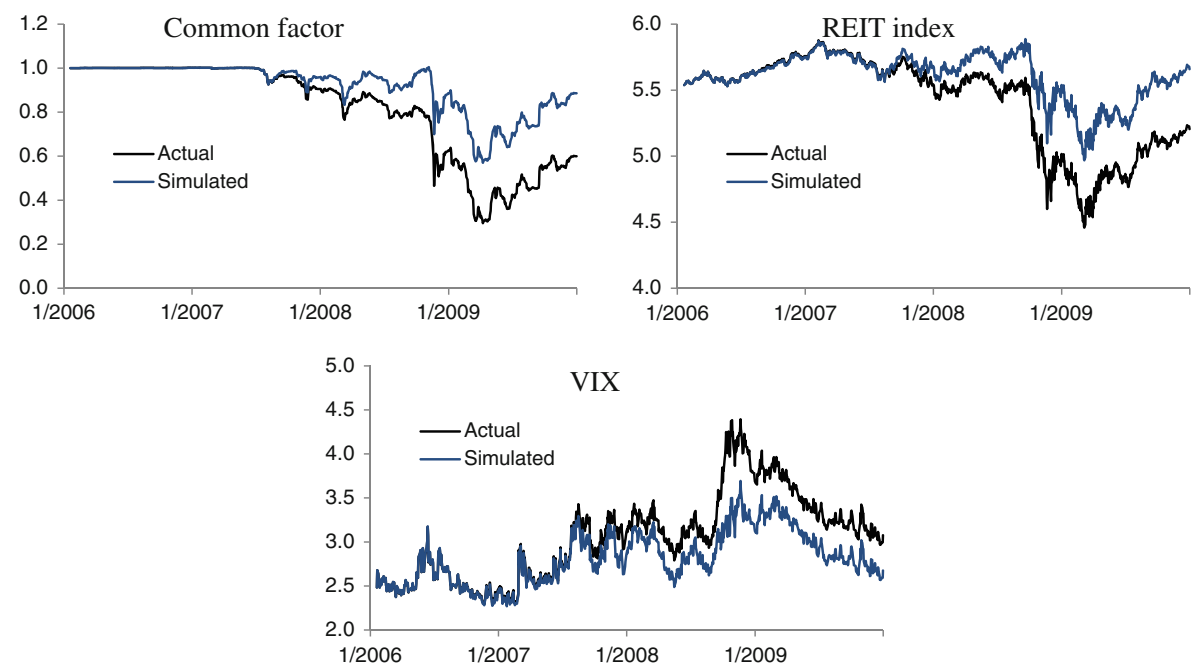

Fig. 6 Actual and simulated values of the common factor, REIT Index and VIX. This figure shows the actual values of the integrated logarithm of the common factor, the logarithm of the Dow-Jones Equity All REIT index and the logarithm of VIX. These actual values are shown on each graph with the simulated value from the estimated vector error correction mechanism in Table 10. The simulated values are from a dynamic simulation with LIBOR less OIS held to its mean value from January 19, 2006 to December 31, 2009

Deviations between Actual and Simulated Values Of the Common Factor, the REIT Index and VIX
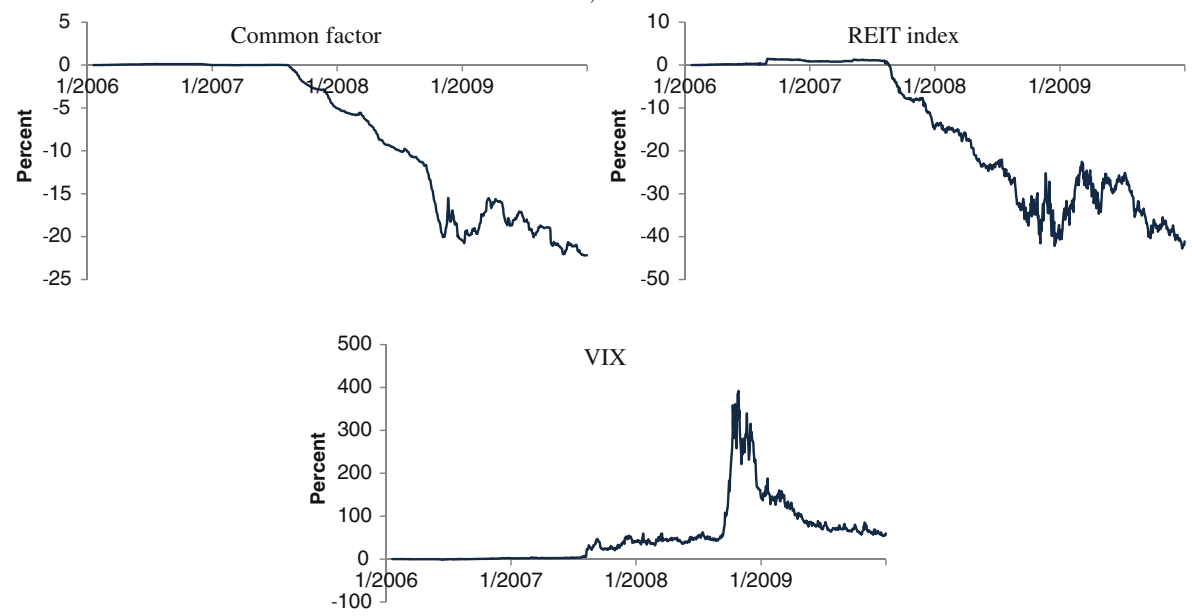

Fig. 7 Deviations between actual and simulated values of the common factor, the REIT index and VIX. This figure shows the percentage deviations between the actual and simulated values of the integrated common factor, the Dow-Jones Equity All REIT index and VIX. The percentage deviations are between the actual values and the exponentiated value of the logarithm of simulated values. The simulated values are from a dynamic simulation with LIBOR less OIS held to its mean value from September 19, 2006 to August 8, 2007. The deviation between the common factor and the simulated value shows a clear downward movement not reversed by the end of 2009. The deviation between the REIT index and the simulated value show a similar downward movement. The deviation between actual VIX and the simulated value shows a dramatic movement upward in 2008, much of which but not all is reversed by the last half of 2009 
shows that the common factor would have been $20 \%$ higher if the LIBOR-OIS had stayed close to its value before the financial crisis. Similarly, the REIT index is slightly more than $40 \%$ lower than it would have been under the simulation. In contrast the VIX is over $50 \%$ higher as a result of the LIBOR-OIS experiences than in the simulation where LIBOR-OIS remained around its pre-crisis values.

Even if LIBOR-OIS returns to pre-crisis values, the cointegrated values of the common factor, the REIT index and VIX need not return to their pre-crisis values even though they will return to the cointegrated relationship. The estimated cointegrating vector suggests that it will take a long time for the variables to return to equilibrium and that the shocks to LIBOR-OIS reflected in the common factor are likely to have permanently changed this factor in the wake of the crisis.

\section{Conclusion}

We characterize the behaviour of the ABX indices of subprime-mortgage backed assets during the Financial Crisis of 2007 and 2008. In the process, we gain a better understanding of the sources of the decline of this market, in particular the falls due to liquidity and counterparty risk. We apply a latent factor model to an unbalanced panel of returns by credit rating and vintage to obtain a measure of the common movement. The unbalanced nature of the data lends itself to identification of four factors from the returns: a common factor, a vintage factor relating to the issuance dates of the securities, a credit rating factor and an idiosyncratic factor.

All factors exert a time-varying influence on the volatility of asset returns. The factor common to all tranches and vintages shows the most important change in variation over time. The common factor's influence on the highly rated tranches increases with the financial crisis, although not dramatically. This is consistent with market participants underpricing, and credit agencies underestimating, the coming financial difficulties. This of course is easier to see now than before the crisis. Given the structure of CDOs, the most senior tranches are quite vulnerable to the miscalculation of common risk. The increasing magnitude of common undiversifiable shocks changes the return behaviour of AAA tranches dramatically as the crisis unfolds. As a result, the demarcation between tranches becomes blurred as assets within the underlying pool becoming increasingly correlated. Consequently, it is the common shock that is most closely associated with the main damage to the values of CDOs. As suggested by Coval et al. (2009), the securitization process led to more vulnerability to common risk that had been unimportant during the low volatility environment before 2007 but came to the fore with a vengeance during the subsequent downturn. At the other end of the spectrum, the role of idiosyncratic shocks in determining asset returns is predominantly associated with the lowest rated tranche, but even this is largely overwhelmed by the common factor after July 2007. Similarly, in the earlier tranquil market conditions, both the ratings and vintage factors are important for some tranches but again their influence is dwarfed by the common factor during the financial crisis.

To estimate the effects of counterparty risk and liquidity difficulties in financial markets, we delve deeper into the origins of the common factor. We relate the common factor to observable variables commonly mentioned as being crucial in 
the initiation and transmission of the crisis, capturing the real estate downturn, general financial market volatility, market liquidity decreases and increasing counterparty risk. The common factor, the REIT index and VIX are cointegrated and related to the LIBOR-OIS spread. The LIBOR-OIS spread played a critical role. Because the spread was elevated during the crisis, at the end of 2009, the common factor was $20 \%$ lower, the REIT index was $40 \%$ lower and the VIX was 50 higher than without the disruptions reflected in LIBOR-OIS. This of course does not imply that setting LIBOR-OIS to pre-crisis values would have reduced the effect on the other variables. Fixing a price cannot help. On the other hand, our results indicate that macroprudential supervision is an even more difficult task than commonly thought. A financial crisis has nontrivial effects that continue well after it is over.

Acknowledgement We are grateful for comments from Paul Koch, Belén Nieto, Ellis Tallman, participants at a conference at Australian National University, a Financial Management Associate conference, a Federal Reserve "Day Ahead" conference on Financial Markets, an INFINITI conference, and a Western Economic Association conference as well as participants in seminars at the Central Bank of Brazil, the University of Tasmania and West Virginia University. We thank Christian Gilles, Paul Kupiec and Charles Smithson for important assistance in understanding the ABX index of CDOs. Dungey acknowledges support from ARC Discovery Grant DP0664024. Dwyer thanks the Spanish Ministry of Education and Culture for support of project SEJ2007-67448/ECON and ECO2010-17158 and the Federal Reserve Bank of Atlanta for research support. Any errors are our responsibility. The views expressed here are ours and not necessarily those of the Federal Reserve Bank of Atlanta or the Federal Reserve System. Author contact details: Dungey: mardi.dungey@utas.edu.au, Dwyer: gpdwyer@gmail.com, Flavin: thomas.flavin@nuim.ie.

\section{Appendix: Details on Data Series}

The data series used in this paper are described below:

ABX Data, all from Bloomberg:

- ABX.HE-A 06-1: 0.54 \% Coupon Closing Price, RED ID: 0A08AFAA7

- ABX.HE-A 07-1: $0.64 \%$ Coupon Closing Price, RED ID: 0A08AFAC0

- ABX.HE-A 07-2: 3.69 \% Coupon Closing Price, RED ID: 0A08AFAD8

- ABX.HE-AAA 06-1: $0.18 \%$ Coupon Closing Price, RED ID:0A08AHAA1

- ABX.HE-AAA 07-1: $0.09 \%$ Coupon Closing Price, RED ID:0A08AHAC6

- ABX.HE-AAA 07-2: $0.76 \%$ Coupon Closing Price, RED ID:0A08AHAD4

- ABX.HE-BBB 06-1: $1.54 \%$ Coupon Closing Price, RED ID:0A08AIAB6

- ABX.HE-BBB 07-1: $2.24 \%$ Coupon Closing Price, RED ID: 0A08AIAC4

- ABX.HE-BBB 07-2: $5.00 \%$ Coupon Closing Price, RED ID: 0A08AIAD2

Other series:

- US Real estate sector price index - Datastream code: DJAREIT

- VIX: CBOE Market volatility index - from Merrill Lynch and the Wall Street Journal.

- Interest rates: 1-month LIBOR; Overnight Index Swap (OIS) rate; 1-month Treasury bill rate; and 1-month Treasury bill rate. LIBOR and OIS rates are from Bloomberg. The Treasury bill rate and AA asset-backed 1-month commercial paper rate are from the Board of Governors of the Federal Reserve. 


\section{References}

Bauwens L, Laurent S, Rombouts JVK (2006) Multivariate GARCH models: a survey. J Appl Econ 21:79109

Benmelech E, Dlugosz J (2009) The alchemy of CDO credit ratings. J Monet Econ 56:617-634

Bhansali V, Gingrich R, Longstaff F (2008) Systemic credit risk: what is the market telling us? Financ Anal J 64:16-24

Brennan MJ, Hein J, Poon S (2009) Tranching and rating. Eur Financ Manag 15:891-922

Brunnermeier MK (2009) Deciphering the 2007-08 liquidity and credit crunch. J Econ Perspect 23:77-100

Chiesa G (2008) Optimal credit risk transfer, monitored finance, and banks. J Financ Intermed 17:464-477

Classens S, Dell'Ariccia G, Igan D, Laeven L (2010) Lessons and policy implications from the global financial crisis. International Monetary Fund working paper WP/10/44

Coval J, Jurek J, Stafford E (2009) The economics of structured finance. J Econ Perspect 23:3-25

DeMarzo P (2005) The pooling and tranching of securities: a model of informed intermediation. Rev Financ Stud 18:1-35

Demyanyk Y, Van Hemert O (2011) Understanding the subprime mortgage crisis. Rev Financ Stud 24:1848-1880

Diebold FX, Nerlove M (1989) The dynamics of exchange rate volatility: a multivariate latent-factor ARCH model. J Appl Econ 4:1-22

Dungey M, Martin VL (2007) Unravelling financial market linkages during crises. J Appl Econ 22:89-119

Dungey M, Pagan A, Martin VL (2000) A multivariate latent factor decomposition of international bond yield spreads. J Appl Econ 15:697-715

Dwyer GP, Tkac P (2009) The financial crisis of 2008 in fixed income markets. J Int Money Finance 28:1293-1316

Dwyer GP, Tkac P (2011) The financial crisis of 2008 and subprime securities. In: Kolb RW (ed) Financial contagion: the viral threat to the wealth of nations. John Wiley \& Sons Inc, New York, pp 229-36

Eichengreen B, Mody A, Nedeljkovic M, Sarno L (2009) How the subprime crisis went global: evidence from bank credit default swap spreads. National Bureau of Economic Research working paper 14904

Fender I, Scheicher M (2009) The pricing of subprime mortgage risk in good times and bad: evidence from the ABX.HE indices. Appl Financ Econ 19:1925-1945

Gorton G (2009) Information, liquidity and the (ongoing) panic of 2007. Am Econ Rev 99:567-72

Hu J (2007) Assessing the credit risk of CDOs backed by structured finance securities: rating analysts' challenges and solutions. Accessed at http://ssrn.com/abstract=1011184 on July 25, 2012

Longstaff FA (2010) The subprime mortgage credit crisis and contagion in financial markets. J Financ Econ 97:436-50

Longstaff FA, Myers B (2009) Valuing toxic assets: an analysis of CDO equity. National Bureau of Economic Research working paper 14871

Longstaff FA, Rajan A (2008) An empirical analysis of the pricing of collateralized debt obligations. J Finance 63:529-563

Lumsdaine RL (1996) Consistency and asymptotic normality of the quasi-maximum likelihood estimator in $\operatorname{IGARCH}(1,1)$ and covariance stationary GARCH(1,1) models. Econometrica 64:575-96

Mian A, Sufi A (2009) The consequences of mortgage credit expansion: evidence from the 2007 mortgage default crisis. Q J Econ 124:1449-1496

Silvennoinen A, Teräsvirta T et al (2008) In: Anderson TG et al (eds) Multivariate GARCH models. Springer-Verlag, Berlin, pp 201-229

Smithson C (2009) Valuing "hard-to-value" assets and liabilities: notes on valuing structured credit products. J Appl Financ 2:1-12

Zhang J, Sanning LW, Shaffer S (2010) Market efficiency test in the VIX futures market. CAMA working paper $8 / 2010$ 